\title{
Effect of a nonsteroidal gametic factor on senile cataract in the dog
}

\author{
GIUSEPPE LUGARO, ${ }^{1}$ MARIA MADDALENA CASELLATO, \\ ERNESTO MANERA, ${ }^{1}$ MARIA ANGELA BACIGALUPO, \\ EDOARDO MASELLI, ${ }^{2}$ AND GIUSEPPE FACHIN ${ }^{3}$ \\ From the ${ }^{1}$ Laboratorio di Chimica degli Ormoni del CNR, via Mario Bianco 9 , \\ I-20131 Milano; ${ }^{2}$ Ospedale Civile di Sondrio, Sezione di Oculistica and \\ ${ }^{3}$ Laboratorio di Fisiologia ed Anatomia, Istituto di Zootecnia, Università̆di Milano, Italy
}

SUMMARY We have studied the clarifying activity of a purified peptide fraction of gametic origin in senile cataract of the dog. The active substance, administered intramuscularly, had significant and durable clarifying effects on the cortical area of the lens.

We have reported ${ }^{12}$ that the male gamete contains one (or more) active substance(s) which counteract(s) temporally and partially some dysfunctions normally occurring in the later part of mammalian life, namely, the so-called senescence phenomena. Since the appearance of senescence varies greatly from individual to individual and is highly timedependent, we decided to analyse one of the more frequent structurally irreversible changes, spontaneous senile cataract, a syndrome that may be evaluated semiquantitatively.

When dogs suffering from senile cataract are injected intramuscularly either with whole homologous semen ${ }^{1}$ or with steroid-, nucleic acid-, and protein-free aqueous extracts of homologous or heterologous spermatozoa ${ }^{3}$ their condition shows a marked remission. We therefore decided to reinvestigate this problem from the point of view of new data we have obtained during recent years.

\section{Material and methods}

The spermatozoa, obtained after centrifugation at $700 \mathrm{~g}$ of bull's semen, were washed twice with saline. After homogenization with corindone and centrifugation at $5000 \mathrm{~g}$, the pooled supernatants (step I) were ultrafiltered through a membrane with a porosity of less than $5 \mathrm{~nm}$ (molecular weight cut off $=10000$ daltons). All steps were carried out at $2^{\circ} \mathrm{C}$.

The ultrafiltrate (step II) was chromatographed on a DEAE-cellulose column at pH 5, with $0.005 \mathrm{M}$ ammonium acetate-acetic acid buffer, and a linear

Correspondence to Dr G. Lugaro, Laboratorio di Chimica degli Ormoni, via Mario Bianco 9, I-20131 Milano, Italy. gradient up to $0.5 \mathrm{M}$ ammonium acetate. ${ }^{4}$ The eluate was divided into 5 fractions; the first eluted fraction (step III), containing the bulk of the activity, was enriched in peptides and free amino acids. The oligonucleotides were eluted with the application of the gradient.

Aliquots of lyophylised fraction from step III, solubilised in $0.005 \mathrm{M}$ ammonium acetate-acetic acid buffer at $\mathrm{pH} 4.5$, were chromatographed according to the method of Gianfranceschi et $a .^{5}$ on spermatozoan-DNA cellulose column prepared as described in Litman. ${ }^{6}$ The active fraction (step IV), eluted in $0.005 \mathrm{M}$ ammonium acetate-acetic acid buffer at $\mathrm{pH} 4.5$, was rechromatographed, after lyophylisation, on Dowex $50 \mathrm{~W} \times 2$ column, yielding at $\mathrm{pH} 4.5$ a highly purified fraction (step $\mathrm{V}$ ). (The same highly purified fraction has been obtained from calf thymus (Gianfranceschi G. L., personal communication), which is a poorer but easily extractable source.)

All the fractions obtained at various stages of purification were assayed intramuscularly ( 2 injections every 12 hours) in senile dogs, 10 or more years old, suffering from spontaneous bilateral corticonuclear opacity of the crystalline lens. 24 hours before and 24 hours and seven days afterwards the eyes were observed with a slit-lamp and with ophthalmoscope under standard conditions at maximum mydriasis in all cases.

We have expressed the results thus obtained semiquantitatively, using an arbitrary scale as follows: $(-)$, nondemonstrable effects; $(+)$, slight and limited clarification of cortical regions in the crystalline lens (approximately $15 \%$ decrease of total opaque area); $(++)$, marked clarification (approximately $30 \%$ decrease); $(+++)$, almost 
Table 1

\begin{tabular}{|c|c|c|c|}
\hline $\begin{array}{l}\text { Fraction } \\
\text { injected }\end{array}$ & $\begin{array}{l}\text { No. of } \\
\text { animals }\end{array}$ & $\begin{array}{l}\text { Dose (as } \\
\text { spermatozoa } \\
\text { equivalent/kg } \\
\text { bodyweight)* }\end{array}$ & $\begin{array}{l}\text { Assessment of improvement } \\
2 \text { t hours later** }\end{array}$ \\
\hline Step II & 8 & $2 \times 10^{\times}$ & 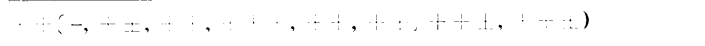 \\
\hline Step III & 8 & $2.5 \times 10^{\times}$ & 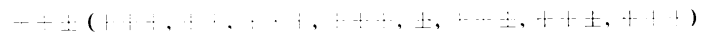 \\
\hline Step III, after trypsin digestion & 4 & $2.5 \times 10^{\wedge}$ & $-(-, \pm,-,-)$ \\
\hline Step III, after papain digestion & 3 & $2.5 \times 10^{\times}$ & $-(-,-,-)$ \\
\hline Step III. after pepsin digestion & 4 & $2.5 \times 10^{\times}$ & $-(-,++,+, \therefore)$ \\
\hline $\begin{array}{l}\text { Step III, after phosphomono- and } \\
\text { phosphodi-esterase digestion }\end{array}$ & 4 & $2 \cdot 5 \times 10^{\kappa}$ & $+t(+++,-,: \leq t,+t+)$ \\
\hline $\begin{array}{l}\text { Step III, after heating } \\
(70 \mathrm{C} \times 10 \mathrm{~min})\end{array}$ & 3 & $2 \cdot 5 \times 10^{\star}$ & 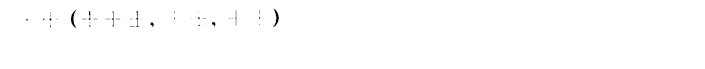 \\
\hline Step V & 3 & $5 \times 10^{\times}$ & $++(++t, t,-+t)$ \\
\hline Placebo & 6 & - & $-(-,-,-,-\perp ?,-,-)$ \\
\hline
\end{tabular}

*1 $\mathrm{ml}$ semen - about $10^{9}$ spermatozoa. **As mean values (in brackets, the individual values).

complete cortical clarification of the crystalline lens (approximately 50\% decrease). The nuclear opacity is usually unaffected.

\section{Results}

Table 1 summarises the clarification values obtained from 43 treated old dogs. An example of marked clarification of the cortical opacity is shown in Fig. 1. The latent period of the effect varies between 6 and 10 hours after the first injection; further clarification may appear after some days.

Tryptic and papain digestion, as well as hydrochloric acid hydrolysis, performed at purification step III, completely destroyed the activity. A lessening of the activity was observed after pepsin treatment. The activity was unaffected by heating at $70 \mathrm{C}$ for 10 minutes in aqueous solution, and by calf intestine phosphomonoesterase and snake venom phosphodiesterase digestion. These experiments showed the presence in the active factor of peptide bonds, the splitting of which abolishes the biological activity.

Such activity cannot be detected in extracts of other tissues (kidney, tongue, heart, and brain), processed up to purification step III, or with glycine, sorbitol, or other pharmacologically inac-

Fig. 1 Photobiomicroscopy of the crystalline lens opacified from senile cataract of dog no. 36 (13 years old, $12 \mathrm{~kg}$ bodyweight), before (B) and 24 hours after (A) the first treatment. Two intramuscular injections in 12 hours of purified gametic fraction step III, each equivalent to $2.5 \times 10^{8}$ spermatozoal $\mathrm{kg}$, obtained as described in the text. The lowering of the cortical opacity appears to be uniform
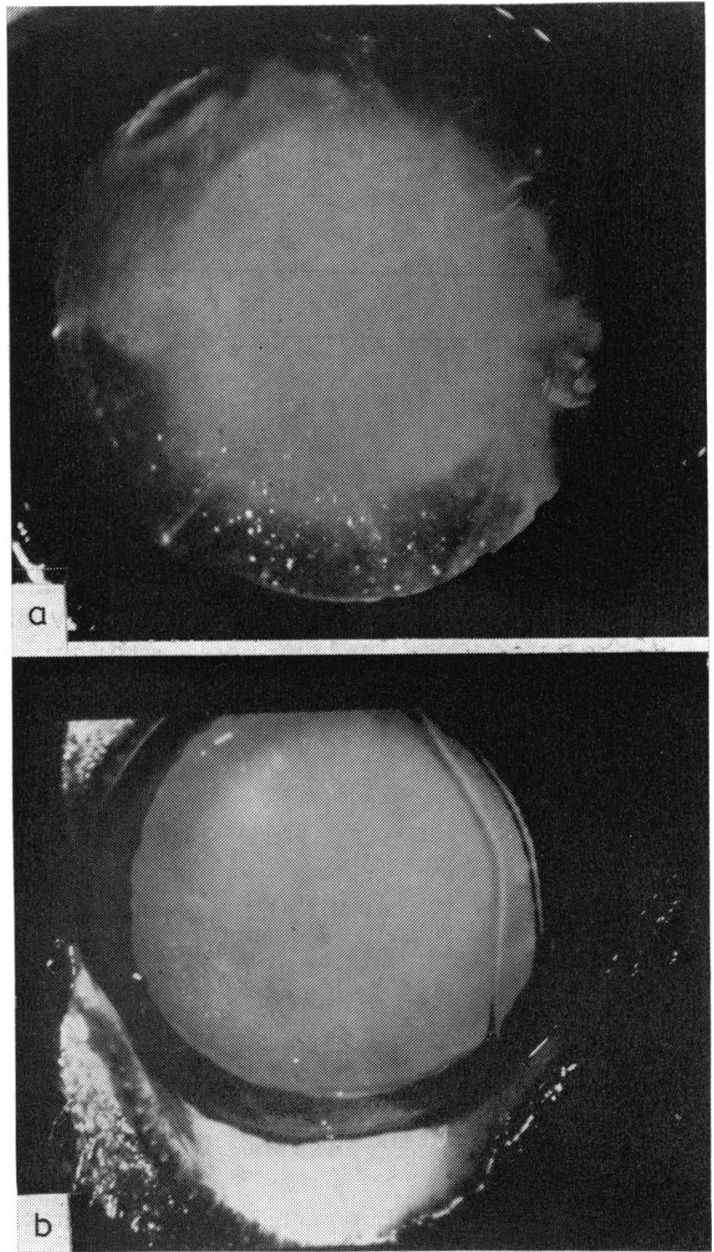


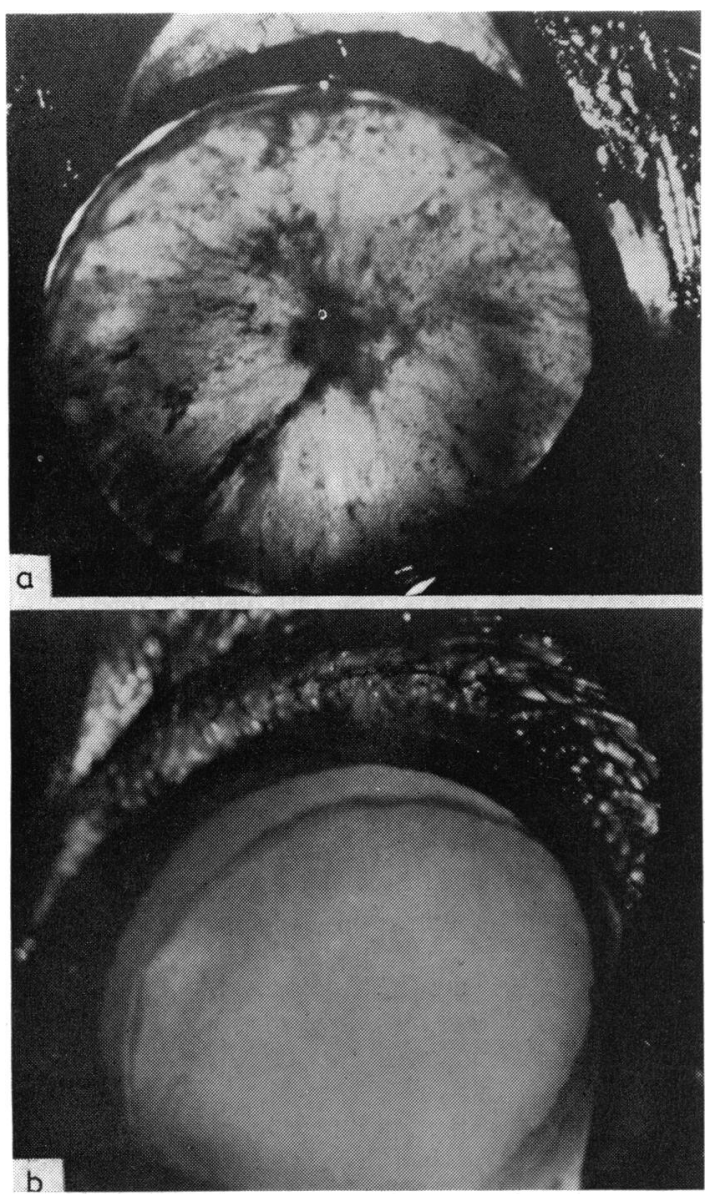

Fig. 2 Photobiomicroscopy of the crystalline lens opacified from senile cataract of dog no. 9 (12 years old, $11 \mathrm{~kg}$ bodyweight), before (B) and 24 hours after (A) the first treatment. Two intramuscular injections in 12 hours of purified gametic fraction step III, each equivalent to $2 \cdot 5 \times 10^{8}$ spermatozoa/kg, obtained as described in the text. The total surface of the crystalline lens indeed appears to be fragmentary.

tive compounds (placebo). This biological activity is not specific for the crystalline lens. Positive responses may also be observed in the appearance of the skin and fur, the avidity of the appetite, the postural tonus, and the general alertness of the animal.

It is interesting to note that sometimes the nuclear and cortical opaque layers in the crystalline lens seemed to become divided into small fragments, with wide transparent spaces between them (Fig. 2).

\section{Discussion}

The phenomenon of partial remission of cataract in the crystalline lens seems to be a specific one, as it follows the increase in specific activity during the purification stages from whole semen. We do not understand the mechanism of this temporary metabolic correction, possibly leading to a partial remission of the signs of senility. But it is worth recalling that similar remissions can be simultaneously observed in many biochemical functions which commonly undergo senile modifications-for example, the lipoprotidaemic spectra ${ }^{7}$ - and more generally in conditions related to slowed-down cytodynamics such as delayed wound healing, ${ }^{9}$ repair of bone fractures, ${ }^{9}$ the induction of some hepatic enzymes (glucokinase, NADPH oxidase, tyrosine amino transferase, 5-aminolevulinic acid synthetase), the activity of which is lessened in senescence (Casellato et al., in press). It is possible that the activity of this (these) principle(s) may concern protein synthesis, but it is not yet clear at what level.

Thus the absolute irreversibility generally thought to be inherent to some metabolic processes, such as senescence, may be questionable, for irreversibility may be partly mitigated by some such factor(s) acting as a homoeostatic regulator(s).

This work was supported by the Programma Finalizzato Biologia della Riproduzione (CNR, Italy).

\section{References}

${ }^{1}$ Fachini G, Gianfranceschi G. Gametes and senescence. Experientia 1964; 20: 404-5.

${ }^{2}$ Fachini G, Carrea G, Gianfranceschi G, Casellato MM, Lugaro G. Information and senescence (proposal of a model). Romanian J Physiol 1977; 14: 193 -205.

${ }^{3}$ Maselli E, Fachini G, Lugaro G. Sugli effetti di un estratto gametico nella cataratta senile. Atti LIV Congresso della Società Oftalmologica Italiana. Roma, 1972.

${ }^{4}$ Lugaro G, Carrea G, Casellato MM, Mazzola G, Fachini G. Evidence for a peptidic factor in spermatozoa inhibiting the ovarian maturation. Biochim Biophys Acta 1973; 304: 719-24.

${ }^{5}$ Gianfranceschi GL, Guglielmi L, Amici D, Bossa F, Bazza D, Petruzzelli R. Low molecular weight peptides controlling transcription are present in the calf thymus chromatin structure. Mol Biol Rep 1977; 3: 429-36.

${ }^{6}$ Litman RM. A deoxyribonucleic acid polymerase from Micrococcus luteus (Micrococcus lysodeikticus) isolated on deoxyribonucleic acid-cellulose. J Biol Chem 1968; 243: 6222-33.

${ }^{7}$ Amici D, Gianfranceschi GL, Marsili G, Michetti L. Young and old rats. ATP, alkaline phosphatase, cholesterol and protein levels in the blood; DNA and RNA contents of the liver. Regulation by an aqueous thymus extract. Experientia 1974; 30: 633-5.

${ }^{8}$ Gianfranceschi GL, Amici D, Guglielmi L. An aqueous thymus extract modifies DNA-proteins interactions in the liver of old rats. Spectrophotometrical data. Experientia 1974; 30: 1049-50.

${ }^{9}$ Teneff $S$. Una terapia biologica aspecifica: analisi di 51 casi. Clin Ter 1970; 53: 491-513. 